\title{
Role of the African Council for Distance Education in Fostering Quality Assurance in Open and Distance Learning in Africa
}

\author{
Ogidan Rotimi ${ }^{1, *}$, Jari Sanusi ${ }^{1}$ \\ ${ }^{1}$ African Council for Distance Education [*Corresponding author. E-mail: rjogidan@acde- \\ edu.org]
}

\begin{abstract}
The African Council for Distance Education (ACDE) was established to promote research, policy and quality in open and distance learning (ODL), so as to increase access to education and training in Africa. This paper discusses the role of the council in fostering establishment of a quality assurance and accreditation agency (QAAA) aimed at addressing concerns for quality in ODL on the continent, so that the society can have confidence in it. The paper discusses the context within which establishment of the council and development of the QAAA were necessitated as well as the policy framework within which the QAAA is being developed. The challenges being experienced in implementing the project are examined and recommendations towards their resolution, and ensuring the success and sustainability of the agency, are made.
\end{abstract}

Keywords: Quality assurance; Open and distance learning; Accreditation; ACDE

\section{$1 \quad$ Introduction}

Quality and the concept of ODL in higher education are almost inseparable by virtue of the features and components. This is because ODL is designed to achieve delivery of significant improvement in terms of increased access to higher education at relatively reduced costs without compromising quality. However, Koul (2005) reported that, the features of flexibility and increased access which make ODL attractive are the same features that constitute a source of suspicion by institutions and the public who are more comfortable with the traditional face to face instructional delivery system. It was also reported by Jegede (2005) that the features of ODL are however, changing to a full-fledged modern day technology- mediated, flexible, learner- driven and self- directed mode of learning. 
The first decade of the $21^{\text {st }}$ century witnessed several positive developments in higher education in Africa. Access was expanded, use of ICT gained increased prominence, several national quality assurance agencies sprouted and the engine of funding was ignited (Evans and Dean, 2003). Similarly, ODL gained increased acceptability as a delivery system and the equity issue was more resolutely addressed. Yet, as the decade closed, the quality of input, process and output remains a major source of concern to the practitioners and other stakeholders in Open and Distance Education.

With regard to expanded access, more institutions were established which opened their doors to over ten percent more students relative to the previous decade. In many African countries like Ethiopia, Kenya, Ghana, Nigeria, Egypt and Tunisia, a minimum of 5\% increase in student numbers was recorded. However, this seems to have barely scratched the surface of the huge demand for placement in higher education. The access challenge continues to loom large. Gains in access, albeit mismatching need, translated into some loss in quality. The quality of graduates produced during the last decade failed to meet labour market expectations and international competitiveness. It is estimated that less than $30 \%$ of the products from the higher education systems across Africa are able to secure employment within two years of graduation as a consequence of inadequate preparation for the labour market and the low absorptive capacity of the market.

As expected, several complimentary events which are aimed at improving the quality of higher education in Africa featured during the last two years of the first decade of Education for all in Africa. One of these is the launch of the Second Decade of Education (2006-2015) by the African Union, the Action Plan of which gave visibility to higher education development in the region. The World Bank also launched its initiative in order to improve the competitiveness of Higher Education in Africa. The Association of African Universities (AAU) supported by partners including the World Bank launched the African Quality Assurance Network (AfriQAN) while the ACDE which was established by Vice Chancellors as stakeholders in African Universities came up with the idea of QAAA.

A significant event which took place at the close of the decade was also the 2009 UNESCO World Conference on Higher Education. The UNESCO BREDA effort was marked with a preparatory meeting which was followed by a conference that brought together stakeholders in the higher education subsector. One of the major conclusions of this regional meeting was that although significant strides were recorded with regard to access, management, quality, funding and equity during the period 1999 to 2009, a yawning gap still exists between where Africa is and where it should be with regards to achieving best practices in the quality of ODL. The World Conference on Higher Education of 2009 noted this observation and in its closing statements, urged that urgent 
steps should be taken to address the quality dimension of higher education in Africa. It is on record that organizations like the CAMES are in existence but they have only been able to address issues of quality assurance at the regional level where they exist whereas, ACDE-QAAA is an African wide initiative that cut across the continent of Africa with the specific mandate to address issues of quality assurance and accreditation in the African Higher Educational institutions

There is also an increasing realization globally of the importance of close cooperation between countries through sharing of resources and technologies to address common problems, and to facilitate the free movement of people. Similarly, there is an increased cooperation through trade and services which has resulted in a corresponding need for education systems to be adapted in response to the demands for trained people with recognized qualifications who are able and ready to move and serve in any part of the world.

The strategy of ACDE to enhance quality among ODL institutions (ACDEQAAA) will assist in driving quality assurance measures, which will ultimately contribute to greater quality of education in Africa. It will help to create a mechanism for benchmarking and comparison of qualifications to foster professional mobility in employment as well as expand job markets. The development of widely accepted standards for quality will also facilitate creation of centres of excellence in Africa.

The establishment of the ACDE-QAAA will benefit Africa because it will allow for greater intra-regional mobility, thereby fostering increased sharing of information, intellectual resources, research, as well as a growing ability to rely on African expertise rather than skills from elsewhere in the world. It will increase access to reliable and transparent information, and promote greater networking among all stakeholders in Quality assurance. This includes creating increased dialogue and cooperation between the higher education systems of different linguistic areas (which have different education systems) thereby, allowing for a more coherent and unified vision for African Quality assurance in higher education.

It is on record that there is an increase in the attention being paid to quality assurance in higher education systems in Africa. For an example, in the last five years, not less than ten countries have established the framework for quality assurance. To maintain the momentum and ensure effectiveness of the efforts, there is need to continually build capacity of persons (old and new) who are involved in the quality assurance enterprise in the region.

Ipaye (2005) reported that the trend in the development of ODL in Africa shows that, the recognition given to quality in ODL in higher education could be as a result of a global emphasis on quality service delivery and the growing concern about the high cost and uncertain benefits of the conventional higher education system. According to him, there is also a clear indication that with 
the way ODL system is designed, it is supposed to possess huge potential to provide enhanced quality education to more people at relatively reduced costs by virtue of its Quality Assurance mechanisms which are inbuilt into its policies, processes and procedures. In ODL, there is a philosophy of viewing quality assurance as a process rather than an activity or event that makes the merits of Quality assurance over and above Quality Control quite palpable. Observation by Koul (2005) shows that, Quality Assurance subsumes Quality control as one of its processes rather than an output. His report shows that, Quality Assurance is structured to achieve good practices and the highest standards in products and services through a set of processes that include monitoring, evaluating and auditing. Similarly, Njoku (2007) asserted that, quality can be described using the elements stated below:

- Fitness for purpose

- Value for money

- Customer satisfaction

- Minimum benchmarks or standards.

It is in this context that there are those who believe that higher education cannot be effectively massified without compromising quality. According to Ojo (2009), the ODL feature of massifying education is not a sufficient issue that should be used to discard the great opportunities that ODL presents especially to countries with huge needs for human capacity development to meet the challenges of the $21^{\text {st }}$ century. This is because, both conventional and ODL tertiary education institutions are faced with the challenges to continue to reinvent themselves in keeping step with the developmental demands of the $21^{\text {st }}$ century, and maintaining quality in instructional delivery as one of the major challenges (Jegede, 2009a). It was also observed by Gbolagade (1999) that the demand crave for quality and credibility in ODL institutions is even more than the requirements of conventional institutions due to the perception that their operational parameters of openness and flexibility give room for lower quality of output. ODL for example according to him, is based on the principle of open access whereby flexible entry qualifications apply and in which exit behaviour is considered to be more important than the entry requirement. It was also opined by Jegede (2005) that, conventional institutions often view their highly selective process of enrolling the best students as a quality control strategy.

Teaching and learning activities in the universities generally show that the task of achieving best practices in assuring quality is not easy as there is a constant need to continue to develop policies and strategies that will ensure optimal throughput of mass access and quality of instructional delivery. Holberge (1989) had reported that, ODL institutions differ from conventional institutions in their operational structures, therefore the strategies and aspects 
requiring Quality Assurance also differ. Therefore according to him, the peculiarities of ODL as observed in administration, management and delivery of teaching/learning activities include:

- Course material development - has the advantage of making use of academic and professional experts, and educational instructional designers to achieve optimal learning outcomes. There is no hidden curriculum and the content is open for public scrutiny.

- Learners' support services - This unit of the ODL ensures that there is quality in the services provided to learners This is done by regularly training instructional facilitators, Counsellors, virtual library services providers, and ICT network staff. These services help in reducing attrition rates and ensuring completion.

- Evaluation and Assessment- the quality of administration and management of the processes of assessing and grading students' performance.

\section{Need for Harmonized Quality Assurance Framework and Policies in ODL Institutions}

The advent of ODL has been marked by individualised effort by practitioners in ODL tertiary education institutions in Africa to enshrine quality assurance in every facet of this mode of educational practice. It was reported by Jegede (2005) that this has resulted in to emergence of different forms, focus, operations and practices. It was in the face of this that a great concern was expressed by practitioners in distance education across Africa particularly to create a forum that will forge out a strategy towards ensuring that ODL institutions in Africa engage in acceptable quality assurance practices through consultation, partnership and collaboration (Jegede, 2009b).

The quality assurance provision by CAMES is only operational among the francophone countries of; Mauritius, Cameroon and Madagascar. It was reported by Ofulue (2011) that the arrangement is over stretched while participation is voluntary, thus lacks mandate to enforce quality standards even in the region. It was also reported by Mhlanga (2011) that, there is highly disparate higher education systems in the Anglophone, Francophone, Lusophone and Arabophone countries. Other observations that are noted in the trend of the quality assurance practices in Africa show that:

- There are presently four Open Universities while, there are forty countries with single/dual mode Distance Learning institutions.

- There is no acceptable standards nor available expertise to regulate quality of Open and Distance Higher Educational Institutions' provisions 
- Although, all the existing quality assurance agencies have responsibility over DL, e-learning and cross border provisions, none has conducted accreditation.

- In most cases, national standards do not exist or are not well developed in African Higher Educational Institutions

- Skills required for developing quality standards and verification of compliance for Distance Higher Education are lacking in most countries

- Capacity building for Quality Assurance in Distance Higher Education is critical

- Capacity for self-assessment is weak

- National QA agency for countries with small tertiary education systems appears not viable

- There is an increase in mobility of students, faculty and labour

- There is need for recognition of degree qualifications across countries (not same degree structures but comparable to the internationally recognized).

\section{Establishment of the ACDE-QAAA}

It was out of great challenge of ensuring that best and acceptable practices in quality assurance are embedded in every activity of tertiary education institutions in Africa where ODL is practiced that the ACDE was established. ACDE is a continental educational organisation comprising African universities and other tertiary education institutions that are committed to expanding access to quality education and training through ODL. The QAAA as an important organ of the ACDE was therefore established as an independent and project driven unit with the mandate to contribute to the development of an indigenous model of quality assurance and accreditation that would serve to position African ODL in the global community.

As explained by Jegede (2009b), the initiative to establish ACDE-QAAA was first muted at a meeting of stakeholders including 10 Government Ministers of Education, 25 vice chancellors from African Universities and other high ranking policy makers, academics with ODL practitioners during the inaugural conference and General Assemblies of the ACDE (10-12 August, 2005) at UNISA in Pretoria. According to him, this was at a time when it became obvious that ODL in higher education in Africa was faced with two major challenges: first, the effective and efficient management of access, quality and cost, and second, need for strategies for the development of shared and common quality assurance conceptions and practices. In addition, ODL Higher Education in Africa is characterised by diverse systems and practices 
that need convergence of understanding and acceptable approaches across the African continent.

Following this, a stakeholders' Workshop was held at the University of South Africa on 21-23 February, 2008.The Planning and Programme Development Workshop also took place at Nairobi from 25 to 29 August, 2008. Consequently, the Stakeholders made recommendations to the ACDE Executive Board which was approved in a special meeting held in October, 2008 in Nairobi (Jegede, 2009b).Thus approval was given to establish the ACDE-QAAA. The Executive Board also declared that the Agency should be hosted in Nigeria by the National Open University of Nigeria. The Federal Government of Nigeria subsequently approved the hosting right and directed that ACDE-QAAA should be included in the annual budget for year 2010 and beyond in order to ensure a proper take off of the agency. Since its establishment, membership of ACDE at the institutional, corporate and individual level have kept on increasing. Thirty higher educational institutions and corporate organisations are members with forty six individuals who are mostly lecturers.

\subsection{Rationale Underlying Establishment of the ACDE-Quality QAAA}

According to Jegede (2009b), in his report of the activities of the ACDEQAAA Working Group, the reasons for establishing the ACDE-QAAA are:

- To ensure that ODL institutions in Africa engage in acceptable quality assurance practices through consultation, partnership and collaboration in distance education;

- To ensure that, the different national and regional policies on ODL will eventually find their point of convergence through the ACDE which, in turn, will provide general direction to the ACDE-Quality Assurance and Accreditation Agency to ensure a common understanding on the issue of quality assurance and accreditation;

- To provide a continental platform for assuring quality, accreditation, articulation and credit transfer within Africa.

- To encourage the establishment and sustenance of national and regional ODL associations for advocacy and policy development.

- To provide ongoing platforms for sharing and creation of ODL resources and programmes for quality assurance and accreditation.

- To ensure the availability and affordability of adequate pool of qualified personnel for peer reviews

- To ensure that the capacity for assessment is strengthened

- Encourage the reconstruction and development of quality assurance practices. 
- Enhance human and financial capacity development among the ACDE member institutions.

- Ensure that a common Quality Assurance framework is developed and entrenched. This will also translate to achieving recognition of qualifications, harmonised African Higher Education system and an enhanced quality of provisions in ODL.

\subsection{Policy Framework}

The policy centres on reviewing and promoting institutional, national, regional and continental quality assurance and accreditation policies, structures and practices for ODL in Africa by identifying and addressing challenges and gaps and draw lessons for the smooth functioning of the continental ODL QAAA. In attempting to sharpen the focus and purpose of the agency, the following five strategic objectives were identified:

- To search for and integrate an appropriate model of quality assurance and accreditation that would position African ODL in the global perspective.

- To develop a broad mandate and governance structure for continental QAAA for ODL in African Higher Education.

- To develop a broad framework for collaboration in the development of ODL quality assurance and code of practices.

- To construct instruments for monitoring and evaluating quality assurance practices in African ODL Higher Education institutions.

- To set up the quality assurance working group as a matter of urgency.

The management structure shown in Figure 1 was adopted for implementing the activities of the ACDE-QAAA. 


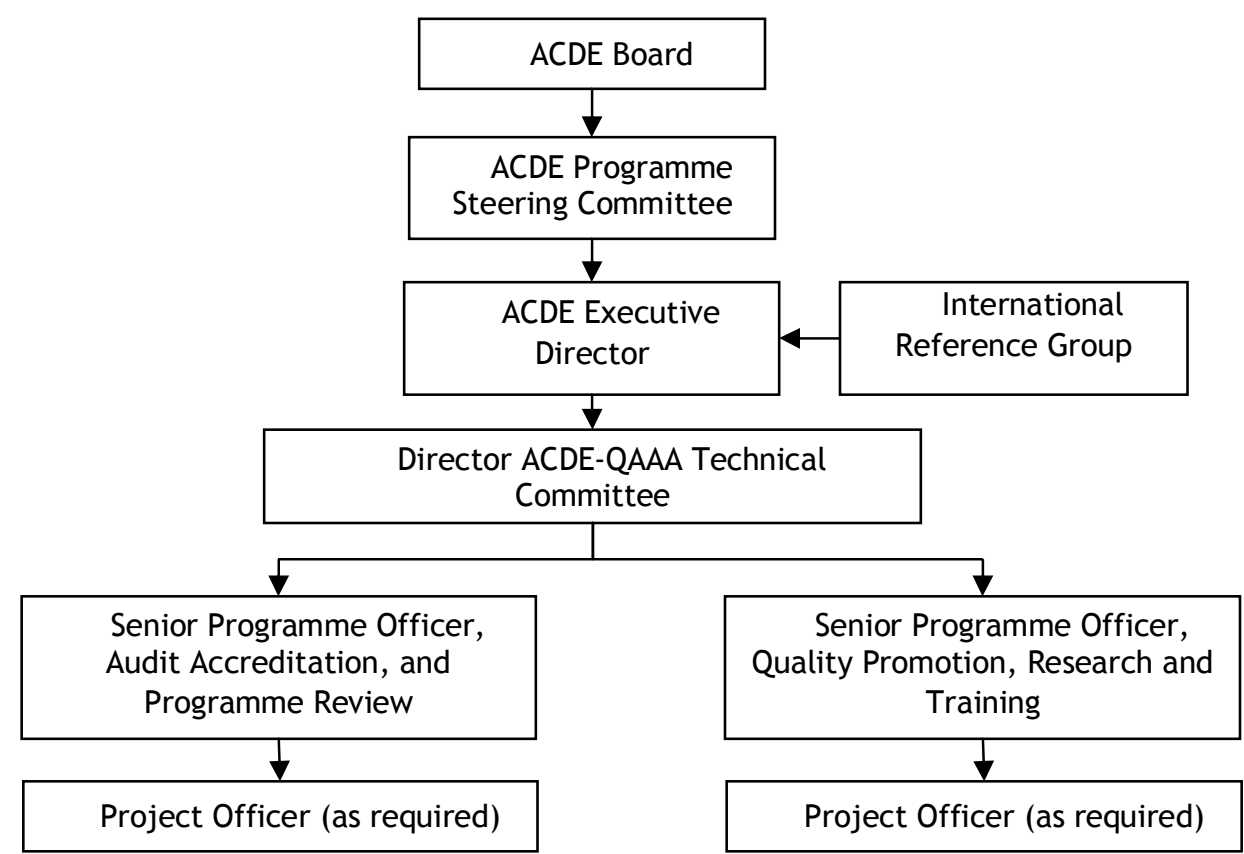

Figure 1: ACDE-QAAA Management Structure

In Figure 1, provision is made for at least five Key staff members who are responsible for the meaningful implementation of the ACDE-QAAA, comprising a QAAA Director, two senior programme officers, and two project officers.

In addition, an International Reference Group (IRG), consisting of key players from ODL counterparts such as the International Council for Distance Education, Commonwealth of Learning, and International Network for Quality Assurance Agencies in Higher Education, European Association for University Lifelong Learning and Australian Universities Quality Agencies is proposed. Its purpose will be to promote collaboration, engender proficiency of the QAAA, and provide critical benchmarking of its conceptual framework and business model within a global quality assurance environment. The IRG will also facilitate identification of international experts to participate in institutional and programme audits and envisaged collaboration initiatives. ACDE Executive Board is the overseer of all issues that concern the activities of the various levels of the organs of the QAAA based on the report submitted to it by the chairman of the Programme steering committee. The ACDE Executive Board carries out deliberations on the critical areas of the reports, takes decisions and provides feedback. It also makes reports available to the General Assembly of the ACDE. 


\subsection{Functions of the ACDE-QAAA}

The functions of the QAAA are to:

- Develop an ACDE-QAAA code of practices, policies and standards, repertoire of instruments and tools to inform the code of practices and establish criteria for the operation and conduct of ODL in Africa;

- Promote the establishment, consolidation, coordination and enhancement of institutional, national, regional and continental quality assurance systems for African ODL;

- Build capacity of higher institutions in quality development and management for African ODL;

- Undertake institutional, national, regional and continental quality assurance audits;

- Promote ethical practices and business standards in the provision of ODL;

- Provide accreditation to institutions and programmes that meet established standards and strive to encourage others to seek accreditation;

- Conduct and promote research for the advancement of quality in distance education and open learning in Africa;

- Promote collaboration and partnerships with international distance learning accreditation agencies to improve quality management and practice in distance education in Africa;

- Constitute an International Reference Group (IRG) for the purposes of promoting collaboration, engendering proficiency and critical benchmarking within a global quality assurance environment; and

- Develop systems and procedures through which learners can transfer credits across African ODL higher institutions.

\subsection{Beneficiaries}

The beneficiaries of the quality assurance initiative of the ACDE are,

- Graduates who shall be able to transfer credits across the African tertiary education system and have their qualifications recognised and affirmed.

- Wider society and key stakeholders such as employers of labour, professional bodies and alumni communities will be valued and responded to in terms of planning and measuring outputs and impacts.

- The management and operations of ODL and other tertiary institutions will be harmonized with consistent and comparable enabling collective growth and development. 
- ODL practitioners, academics and researchers will have certified competencies as Quality Assurance specialists who are able to make significant contributions to systems' development.

- Consolidated and legitimized ACDE as the official voice and platform for ODL in Africa, which will be able to represent African positions and concerns in engagements as equals with international counterparts.

- Strengthened and continuously developed regional, national and institutional ODL Quality Assurance bodies.

- Provide ODL Quality Framework and supporting tools to guide further harmonization and development among higher education and research institutions such as AAU, COL, RETRIDAL, SARDEC, etc.

\subsection{Sustainability Plan}

In order to be able to sustain this agency (ACDE-QAAA), member institutions and Government of the host country regularly donate seed-funds for the initial start-up phase. Very central to the sustainability of the agency is the fact that, implementation of the work plans was carried out as stipulated in the project document (Jegede, 2009b). Similarly, beneficiaries are expected to cover the cost of ACDE-QAAA activities conducted in the institutions or conducted by ACDE-QAAA experts on their behalf.

\subsection{Process and Benefits of Collaborating to establish ACDE-QAAA}

It has been very beneficial for ODL institutions to collaborate and work together because ACDE-QAAA is well positioned to facilitate the process of achieving the goal of integrating an indigenous model of quality assurance and accreditation that would position African ODL in the global perspective and develop a broad framework for collaboration in the development of ODL quality assurance and code of practice. Collaboration would be fostered through the following approaches;

- Invite experts from the various ODL institutions to join the team of assessors during accreditation exercises.

- Involve experts from other Universities [and other higher education institutions] in some activities particularly in programme development.

- Getting prompt feedback from ACDE-QAAA on the performance of an institution after the accreditation exercise.

- Promote exchange of ideas between the Agency and educational institutions on the development and assurance of quality in Africa higher education in all its dimensions. 
- Build capacity and share knowledge in teaching, research, and community outreach among the ODL institutions.

- pull resources and develop programmes in capacity development

- Proliferate opportunities for learning, scholarship and academic exchange in ODL.

- facilitate credit transfer between distance learning institutions across Africa

- Provide enabling environment to administer examinations of different ODL institutions in member institutions of ACDE.

\subsection{Activities of the Agency}

The following are the activities of the ACDE-QAAA that have been carried out or are on-going,

- Regular advocacy and sensitization through presentation of position papers in the Commonwealth of Learning and ICDE workshops.

- Providing representation for all ODL higher education institutions and individuals in Africa through quality provisioning that is in the process of achieving a convergence of understanding and approaches for continental development. Hitherto the establishment of ACDE-QAAA, ODL Higher Education in Africa is marked by diverse systems and practices.

- Creation of point of convergence for the different national and regional policies on ODL through the ACDE which, in turn, gives general direction to the ACDE-QAAA to ensure a common understanding of the issue of quality assurance and accreditation.

- Develop a continental platform for assuring quality, accreditation, articulation and credit transfer within Africa. It is in the process of establishing a sustained national and regional ODL association for advocacy and policy development. This will further provide platforms for sharing and creation of ODL resources and programmes for quality assurance and accreditation.

- Fostering of regional collaboration in ODL so as to contribute to the development of policies and practices that are essential to the advancement of quality that will help to harmonise and strengthen all ODL operations.

- Provide a common front to address issues of accessibility, cost, accreditation, resource sharing, flexibility, training needs, infrastructural development, and articulation of programmes and credit transfer among member institutions. 
- Develop an acceptable Quality Assurance model for the ODL higher educational institutions in Africa.

\section{Challenges}

The ACDE-QAAA is certainly facing some challenges partly because it has just been established. Some of the challenges are stated below:

- Need for buoyant financial resources for carrying out project activities of the Agency. This is because ACDE is an international Non Governmental Organization which basically depends on financial supports from member institutions, donations from agencies and Federal Government of the member institutions, and membership subscription. Please see the attachment on membership in the appendix.

- Capacity Building of experts in ODL who will turn out to be Quality Assurance practitioners requires time and fund to accomplish.

- Need to develop a widely acceptable model that can be used to carry out accreditation of ODL higher education institutions in Africa. This indeed requires time, fund, human capital resources and expertise.

- Need to correct the wrong perception of the quality of ODL products by academics, the employers of labour and the society. This requires determination and consistency in the campaign for adherence to best practices among the ODL member institutions.

\section{$5 \quad$ Recommendation}

The roles of the ACDE in fostering quality assurance in African ODL so far has shown that great benefit avail in collaboration among the tertiary education institutions where ODL is practiced in Africa. It is also obvious that no ODL system can be successful without strict adherence to the application of Quality Assurance mechanisms that have been built into its processes from policy and planning framework to learners' entry and completion of study. It is therefore recommended that ACDE-QAAA should intensify effort in playing her role to,

- Enhance quality assurance practices in teaching and learning by promoting uniform practices and standards that are in tune with the objectives of the agency.

- Encourage technology mediated learning in order to maximize the learning process. 
- Put in place a sustainable programme that will ensure availability of quality of staff through training and exchange programme at the national and regional level.

- Encourage member institutions to adhere to the practice that will ensure quality of course content development and editing of study materials.

- Embark on activities that will improve on the quality of support services and facilitation of learning through the development and use of training manuals.

- Organize seminar and training regularly in the area of internal self review processes and inform member institutions on how to prepare for, and meet the criteria for external audits and assessments

\section{Conclusion}

There is no doubt that in the current knowledge driven economy, the global community will increasingly demand for higher standards in service delivery, thus making Quality Assurance to remain a pertinent issue for ODL higher education delivery. It is also clear that Africa has recognised the need and value of assuring quality of ODL higher education by establishing ACDE-QAAA. Following this and as clearly stated in the communique of the $2^{\text {nd }}$ ACDE Conference July 2008, the ACDE general assembly called upon the Commonwealth of Learning to strengthen its collaboration with and support for ACDE in the actualization of its mandate especially in operationalising the Consortium of African Open Universities and the Continental Quality Assurance and Accreditation initiatives (ACDE Conference Proceedings, 2008). The establishment of ACDE-QAAA is indeed timely and forthright. It is certain that if it is able to live up to its mandate of helping to forge a common forum for uniform practice and assist in the establishment and sustenance of quality assurance agencies among ODL higher education institutions at the national and regional levels in Africa, then, the scepticism against ODL programmes and institutions by individuals and the public would be corrected

\section{References}

Evans, J. R., Dean. J. J. W. (2003). Total quality management, organization and strategy. Mason Thomphson: South-Western College Publishing.

Gbolagade, A. (1999). A glimpse into the Future of Distance education in Africa. FID Review 1 (2/3), 110-115. 
Ipaye, B., (2005). Study Guides and Learning Strategies in Open and Distance Learning. Lagos: Chaoobi Publishers.

Jegede, O. (2005). Induction workshop for the Staff of the National Open University of Nigeria. London: Commonwealth of Learning.

Jegede, O. J. (2009a). The technology race: expanding opportunities or deepening the divide? Paper presented at the World Conference on Higher Education (WCHE 2009): 'The New Dynamics of Higher Education and Research for Societal Change and Development' held at UNESCO Headquarters, Paris. 5-8 July 2009.

Jegede, O. J. (2009b). The Role of Open and Distance Learning in Achieving Vision 20-2020 (through 7-point Agenda, MDGs, EFA Goals and NEEDS2). Lead paper presented at the 2-day advocacy workshop on Open and Distance Learning in Nigeria: 'The Role of Open and Distance Learning in Achieving Vision 20-2020' held at the National Open University of Nigeria, Abuja Office on 28-29 April 2009.

Koul, B. N. (2005). Higher Distance/Virtual Education in the Anglophone Caribbean. Caracas: .International .Institute for Higher Education in Latin America and the Caribbean.

Mhlanga, E. (2011). Rationale for the development of a common Quality Assurance Framework for Africa. Paper presented at the $3{ }^{\text {rd }}$ ACDE-QAAA workshop held at the Hilton Hotel, Nairobi on 27-29 ${ }^{\text {th }}$ June 2011.

Njoku, P. C. (2007). Open and Distance Learning (ODL) quality assurance models and international case studies. Paper presented at the COLRETRIDAL workshop on Quality Assurance (QA) in Open and Distance Learning (ODL) held at the University of Education, Winneba, Ghana on February $14-15^{\text {th }}, 2007$.

Ofulue, C. I. (2011). An overview of quality assurance on the continent. $2^{\text {nd }}$ ACDE-QAAA workshop: 'Development of Tools and Instruments' held at Lagos, Nigeria. 16-20 April, 2011.

Ojo, A. (2009). Harvesting the Open University System for National Empowerment. Convocation Lecture delivered on the occasion of the first graduation ceremony of the National Open University of Nigeria (NOUN) on 6 January, 2009. 
